\title{
KAPALI ALAN KONUMLANDIRMA SISTEMLERİ İÇİN DÜĞÜM PROTOTİPİ GELİŞTİRME
}

\author{
İsmail KIRBAŞ ${ }^{*}$, Kadir ARSLAN² \\ ${ }^{1}$ Burdur Mehmet Akif Ersoy Üniversitesi, Mühendislik Fakültesi, Bilgisayar Mühendisliği Bölümü, Burdur, \\ Türkiye \\ ${ }^{2}$ Burdur Mehmet Akif Ersoy Üniversitesi, Mühendislik Fakültesi, Malzeme Teknolojileri Mühendisliği Bölümü, \\ Burdur, Türkiye
}

\begin{tabular}{|c|c|}
\hline Anahtar Kelimeler & Öz \\
\hline $\begin{array}{l}\text { Wi-Fi, } \\
\text { Bluetooth, } \\
\text { Makine Öğrenmesi, } \\
\text { Kapalı Alan } \\
\text { Konumlandırma, } \\
\text { Prototip Geliştirme. }\end{array}$ & $\begin{array}{l}\text { Kablosuz haberleşme sistemleri günümüzün en çok kullanılan ve hızla gelişen } \\
\text { teknolojileri arasında bulunmaktadır. Kablosuz sistemlerdeki ve donanımsal } \\
\text { malzemelerdeki gelişmeler ile düşük maliyetli, düşük enerji tüketimli ve } \\
\text { kurulumları kolay kablosuz ağlar tasarlanarak bir ortamdaki farklı fiziksel veriler } \\
\text { elde edilebilmektedir. Nesnelerin bulundukları yerleri tespit etmek amacıyla } \\
\text { kullanılan konumlandırma sistemleri, kablosuz teknolojileri kullanmaktadır. } \\
\text { Günümüzde konumlandırma sistemlerinin kullanımı giderek artmakta ve } \\
\text { yaygınlaşmaktadır. Illk olarak açı alanlarda konum belirlemek için kullanılan GPS } \\
\text { uydu sistemleri geliştirilmiştir. Bu sistem dünya genelinde askeri ve sivil } \\
\text { uygulamalarda yaygın olarak kullanılmaktadı. Açlk alan konumlandırma da } \\
\text { genellikle uydu sinyallerinden faydalanılır ve sinyallerin geliş süresi üzerinden } \\
\text { konum tespiti gerçekleştirilir. Ancak kapalı alanlar söz konusu olduğunda farklı bir } \\
\text { yaklaşım ve çözüm geliştirilmesi gerekmektedir. Çalışmamızda kapalı alanlarda } \\
\text { konum belirlemek amaçıla Wi-Fi ve Bluetooth sinyallerinden yararlanan üç ayr } \\
\text { donanım geliştirilmiştir. Makine öğrenmesi yöntemleri kullanarak yapılan } \\
\text { denemeler, kapalı alanda konum belirlemek için geliştirilen donanımların 1-1,5m } \\
\text { aralığında bir hata ile konum tespiti yapabildiğini göstermektedir. }\end{array}$ \\
\hline
\end{tabular}

\section{DEVELOPING NODE PROTOTYPE FOR INDOOR POSITIONING SYSTEMS}

\section{Keywords}

Wi-Fi,

Bluetooth,

Machine Learning,

Indoor Positioning,

Prototype Development.

\begin{abstract}
Wireless communication systems are among the most used and rapidly developing technologies of today. With the advances in wireless systems and hardware materials, different physical data in an environment can be obtained by designing low cost, low energy consumption and easy to install wireless networks. Positioning systems used to detect the locations of objects use wireless technologies. Today, the use of positioning systems is increasing and becoming widespread. Firstly, GPS satellite systems that are used to determine the location in open areas were developed. This system is widely used in military and civilian applications worldwide. In open field positioning, satellite signals are generally used and position determination is performed over the arrival time of the signals. However, when it comes to closed areas, a different approach and solution should be developed. In our study, three separate equipment using Wi-Fi and Bluetooth signals were developed to determine the location in closed areas. Experiments using machine learning methods show that the equipment developed to determine the location in the indoor area can detect locations with an error in the range of $1-1.5 \mathrm{~m}$.
\end{abstract}

\section{Alıntı / Cite}

Kırbaş, İ., Arslan, K., (2020). Kapalı Alan Konumlandırma Sistemleri için Düğüm Prototipi Geliştirme, Mühendislik Bilimleri ve Tasarım Dergisi, 8(2), 612-624.

\footnotetext{
* ilgili yazar / Corresponding author: ismailkirbas@mehmetakif.edu.tr, +90-248-213-2751
} 


\begin{tabular}{l|l|l}
\hline Yazar Kimliği / Author ID (ORCID Number) & \multicolumn{3}{|l}{ Makale Süreci / Article Process } \\
\hline İ. Kırbaş, 0000-0002-1206-8294 & Başvuru Tarihi / Submission Date & 12.01 .2020 \\
K. Arslan, 0000-0002-9629-1839 & Revizyon Tarihi / Revision Date & 22.05 .2020 \\
& Kabul Tarihi / Accepted Date & 06.06 .2020 \\
& Yayım Tarihi / Published Date & 25.06 .2020 \\
\hline
\end{tabular}

\section{Giriş (Introduction)}

Nesnelerin bulundukları yerleri tespit etmek ve onları gerçek zamanlı olarak yönlendirmek için konumlandırma sistemleri kullanılmaktadır. Açı alanlarda bir nesnenin konumunu tespit edebilmek için GPS, GLONASS gibi uydu tabanlı konumlandırma sistemleri kullanılmaktadır. Uydu tabanlı sistemler ile nesnelerin gerçek konumunun tespit edilebilmesi için uydular ile konumu tespit edilecek nesne, görüş hattında olması gerekmektedir. Çatılar, duvarlar gibi uydu görüşünü engelleyen yapılardan dolayı uydu tabanlı konumlandırma sistemleri kapalı alanlarda kullanılamamaktadır (Başak, 2017). Bu nedenle kapalı alanlardaki nesnelerin konum tespiti için, uydu tabanlı sistemlerden bağımsız olarak, Wi-Fi, Bluetooth, Zigbee, UWB, RFID vb. tabanlı kablosuz teknolojiler kullanılarak birçok çalışma yapılmıştır. Kapalı alanlar için henüz standartlaşmış bir konumlandırma sistemi olmamakla birlikte bir sitemden temel beklentiler; yüksek doğruluk, yüksek güvenlik, düşük maliyet, düşük güç tüketimi, düşük bakım ihtiyacıdır (Türkoral vd., 2016). Teknolojideki gelişmelerle birlikte kablosuz cihazlar daha ucuz ve daha düşük enerji tüketimli olarak üretilebilmektedir. Çalışmamız kapsamında kapalı alanlardaki nesnelerin konum tespiti için parmak izi konumlandırma yöntemini temel alan Wi-Fi ve Bluetooth (BLE) tabanlı donanımlar geliştirilmiștir. Bu amaçla konumlandırma yapılacak alana yerleştirilmek üzere dügüm cihazları, konumlandırma yapılacak alanın sinyal haritasını olușturmak amacıyla saha analiz cihazı ve konumu tespit edilmek istenen nesneye takılacak olan kablosuz takip cihazı geliştirilmiştir. Geliştirilen tüm cihazlar istenildiği takdirde Wi-Fi veya Bluetooth moduna alınabilmektedir. Böylece hem Wi-Fi hem de Bluetooth tabanlı konumlandırma sistemi tek bir konumlandırma paketi kullanılarak gerçekleștirilebilmektedir.

\section{Kapalı Alan Konumlandırma (Indoor Positioning)}

Radyo dalgaları, manyetik alanlar, akustik sinyaller, mobil cihazlar aracıllğıyla toplanan sensör verileri kullanılarak kapalı bir alandaki nesneleri veya kișilerin konumlarının tespit edilmesi, kapalı alan konumlandırma olarak tanımlanmaktadır. Kapalı alan konumlandırma sistemleri hava alanları, tren istasyonları ve bina içlerinde yönlendirme yapmak, müzelerde ziyaretçi deneyimini artırmak, üretim ve depo sistemlerinde kontrolü sağlamak, görme engelliler için yönlendirme gibi uygulamalar ile kapalı alanlarda nesnelerin konumunu tespit etmek ve yönlendirmek amacıyla kullanılmaktadır (Dükkancı ve Kırbaș, 2018).

Kapalı alan içerisindeki nesnelerin konumlarını tespit edebilmek ve onları gerçek zamanlı olarak yönlendirebilmek için konumlandırma yapılacak alandaki sabit ve hareketli cihazlardan gelen sinyalleri elde etmek gerekmektedir. Bu nedenle sinyal ölçüm teknikleri kullanılmaktadır. Kapalı alan konumlandırma sistemlerinde kullanılan sinyal ölçüm teknikleri arasında geliş süresi, geliş süresi farkı, geliş açısı, gidiş-dönüş zamanı, alınan sinyal gücü göstergesi (RSSI) yaygın olarak kullanılan sinyal ölçüm teknikleridir. Konumlandırmanın yapılacağı kapalı alana, beklenen hassasiyete, maliyet ölçütlerine göre gereksinimleri karşılayabilecek ideal bir sistem tasarımı yapılması gerekmektedir (Arslan, 2019; Arslan ve Kirbaș, 2016).

Kapalı alan konumlandırma sistemleri farklı șekillerde tasarlanabilmektedir. Konumu bulunmak istenen nesneler tarafından gönderilen sinyal bilgileri, konumu önceden bilinen sabit düğümler tarafından alınması ve bu cihazların gerekli hesaplama işlemlerini yapmasıyla konumlandırma yapılabileceği gibi konumu önceden bilinen sabit düğüm noktalarından alınan sinyallerin, konumu tespit edilmek istenen nesne tarafindan alınmasıyla da konumlandırma yapılabilmektedir. Konumlandırma yapılacak tekniğe göre konumu önceden bilinen sabit cihaz ya da konumu bulunmak istenen nesne gerekli hesaplamaları kendisi yapabileceği gibi alınan sinyal özelliklerini merkezi bir cihaza göndererek konumlandırma hesaplarını merkezi cihaz da yapabilir (Kırbaş ve Dükkancı, 2019). RSSI tekniği, kapalı alan konumlandırma sistemlerinde nesnelerin konumlarının tespit etmek için sıklıkla kullanılan bir sinyal ölçüm tekniğidir. Wi-Fi, Bluetooth gibi birçok teknolojide standart bir özellik olarak bulunan RSSI değeri, harici bir donanım gerektirmeden elde edilebilmektedir. Bu nedenle RSSI ölçüm tekniğine dayanan konumlandırma sistemleri zaman ve maliyet açısından kolaylık sağladığı için diğer sinyal ölçüm tekniklerine göre daha fazla tercih edilmektedir. Bu çalışma kapsamında geliştirilen konumlandırma cihazları sinyal ölçümlerinde RSSI tekniğini kullanmaktadır.

Parmak izi yöntemi ise, eğitim aşaması ve konumlandırma aşaması olmak üzere iki bölümden oluşmaktadır. Eğitim aşamasında kapalı alanın karakteristiğini oluşturan bir referans sinyal şiddet haritası oluşturulur (Kolodziej ve Hjelm, 2006; Yücel vd., 2014). Bu aşamada kapalı alan içerisindeki ızgara şeklinde belirli aralıkla referans noktalarına yerleştirilen sabit cihazlardan ölçümler alınır ve bu ölçümler bir sunucuya kaydedilerek eğitim aşaması tamamlanır. Bu işlemler saha analizi olarak adlandırılmaktadır. Konumlandırma aşamasında, konumu 
bulunmak istenen cihaz ile referans noktalarına yerleştirilen cihazların sinyal şiddetleri ölçülür ve bu ölçümler saha analiz aşamasında sunucuya kaydedilen sinyal şiddeti haritasında hangi noktaya en yakın olduğu tespit edilerek konumlandırma yapılır. Açıdan ve mesafeden bağımsız olarak konumlandırma yapan parmak izi yöntemi ile gerçekleștirilen konumlandırma sistemlerinde, kapalı alanın karakteristiğini oluşturan eğitim aşamasında elde edilen sinyal sayısı ve sinyal yayan vericilerin sayısının artması konumlandırma doğruluğunu artırabilmektedir (Mautz, 2012; Sakpere vd., 2017). Ölçülen sinyallerin, eğitim aşamasında oluşturulan haritadaki sinyaller ile benzerlik analizi yapılırken konum tahmin doğruluğunu artırmak için yapay sinir ağları (YSA), K-en yakın komşu (K-EYK), Rassal orman gibi makine öğrenmesi yöntemleri kullanılmaktadır. Wi-Fi ve Bluetooth cihazlarından RSSI değerleri kolaylıkla elde edilebildiğinden dolayı, kapalı alan konumlandırma sistemlerinde parmak izi yöntemi en sık kullanılan yöntemdir.

Parmak izi yönteminin eğitim aşaması olarak bilinen, çalışma alanının sinyal haritasının oluşturulması için statik ve dinamik tarama olmak üzere 2 farklı sinyal haritası oluşturma yöntemi bulunmaktadır. Dinamik taramada x ve y koordinatları girilmeden sürekli olarak saha içerisinde belirli bir hız ve doğrultuda hareket edilerek, tarama cihazı tarafından sabit dügümlerden alınan sinyal değerleri belirli aralıklarla sunucu cihaza gönderilmektedir. Daha sonra bu sinyal verilerine $\mathrm{x}$ ve y koordinatları eklenerek haritalama işlemi tamamlanır. Dinamik tarama çok geniş alanlarda kullanıldığında tarama süresini kısaltarak zaman tasarrufu sağlamaktadır. Statik taramada ise önceden belirlenen $\mathrm{x}$ ve y koordinatlarından sinyal verilerinin alınarak sunucu cihaza gönderilme işlemidir. Statik tarama işleminde bir noktadan birçok sinyal verisi elde edilerek daha doğru sonuçlara ulaşıllabilir (Doğancl, 2008). Radyo dalgalarının yol kaybı, kapalı ve açık alanlarda alıcı ile verici arasındaki mesafenin artmasıyla birlikte logaritmik olarak artmaktadır. Yol kaybı alıcı ve verici arasındaki değişken mesafe ve yol kayıp katsayısı (n) cinsinden ifade edilmektedir. Logaritmik yol kayıp modeli Denklem 1'de gösterilmektedir.

$$
P_{L}(d B)=P_{L}\left(d_{0}\right)+10 n \log \left(d / d_{0}\right)
$$

d alıcı ve verici arasındaki mesafe, $n$ yol kayıp katsayısıdır ve sinyalin yayıldığı ortama bağlıdır, $d_{0}$ daha önceden ölçümleri yapılmış bilinen referans uzaklıktır (Gu vd., 2009).

Literatür taramasında, Lashkari ve arkadaşları bir binadaki kişinin Wi-Fi sinyallerini kullanarak konum tespiti için mobil uygulama önermektedirler (Lashkari vd., 2010). Bekkelien Bluetooth tabanlı teknolojiler ile kapalı alan konumlandırma sistemi geliştirmiş ve 1.5 metre hata ile konum tespiti gerçekleștirmiştir (Bekkelien, 2012). Üçgenleme yöntemi ile Bluetooth Low Energy (BLE) tabanlı konumlandırma sistemi tasarlayan Salas, 1 1,5 metre hata ile konumlandırma gerçekleștirmiştir (Corbacho Salas, 2014). Taşkın akıllı telefon ile haberleșen BLE tabanlı konumlandırma sistemi geliştirmiş ve kapalı bir alanda konumlandırma testleri gerçekleştirmiştir (Taşkın, 2017). Michaelsson ve Quiroga kapalı bir çiftlik içerisinde testlerini gerçekleştirdikleri hayvan takip sisteminde enerji tüketimini optimize ederek ticari bir ürün geliştirmeyi amaçlamışlardır (Michaelsson ve Quiroga, 2017). Aydın ve Erkmen tasarladıkları donanım ile bir yayadan, hareket sensörleri ile elde ettikleri verileri kullanarak kişinin yürüdüğü yolu GUI ortamında çizdirmişlerdir (Aydin ve Erkmen, 2019).

\section{Geliştirilen Kapalı Alan Konumlandırma Cihazları (Developed Indoor Positioning Devices)}

Çalışmamıza konu olan kapalı alan konumlandırma yaklaşımı Wi-Fi ve Bluetooth sinyallerinin gönderim kuvvetlerinin (RSSI) ölçüldüğü ve buna göre uzaklıkların kestirildiği bir yaklaşım olan parmak izi metoduna dayanmaktadır.

Bluetooth, kısa mesafelerde RF ile haberleşme sağlayan, IEEE 802.11.5 standartlarını kullanan bir haberleşme protokolüdür. Bluetooth teknolojisi lisanssız olarak kullanılan $2.4 \mathrm{GHz}$ Endüstriyel, Bilimsel, Sağlık (ISM) bandında çalışmaktadır. 1994 yılında tasarlanan Bluetooth'un geliştirilmesi SIG kuruluşu tarafından sağlanmaktadır (Dahlgren ve Mahmood, 2014). Düşük güç tüketimine sahip ve fiyatları oldukça düşük olan Bluetooth cihazları, 2.4 $\mathrm{GHz}$ ile $2.48 \mathrm{GHz}$ arasındaki 80 adet frekans bandını kullanabilmektedir. Illk Bluetooth haberleşme protokolü Bluetooth temel hız / geliștirilmiş veri hızı (BR/EDR) sistemi Bluetooth Classic olarak tanımlanmaktadır. 2010 yılında Bluetooth Low Energy (BLE) kullanıma sunulmuştur. Bilgisayarlar ve mobil cihazlar ile birlikte gömülü olarak gelen ve günlük hayatta sıklıkla kullanılan Bluetooth teknolojisinin en büyük avantajlarından biri düşük enerji tüketimidir. BLE teknolojisi ile birlikte Bluetooth cihazlarının kapsama alanları genişletilirken enerji tüketimleri azalmıştır.

Wi-Fi haberleşmenin temelleri ise IEEE tarafından 1980 yllında IEEE 802 komitesi oluşturulmasıyla atılmıştır (Kim ve Lee, 2015). Çalışmalar sonucunda kablosuz yerel alan ağı (WLAN) haberleşme protokolü geliştirilmiştir. WLAN sınırlı bir alanda, çift yönlü olarak $2.4 \mathrm{GHz}$ ve $5 \mathrm{GHz}$ radyo frekans bantlarını kullanarak geniş bantta veri iletimi sağlayan bir haberleşme protokolüdür (Bulucu ve Kavas, 2007). Wi-Fi teknolojisi de bilgisayarlar ve mobil cihazlar ile birlikte gömülü olarak gelmektedir. Bu teknolojisinin, günümüzde her yerde kullanılması, geniş ürün 
çeşitliliğine sahip olması, yüksek bağlantı hızlarına ulaşabilmesi ve internete doğrudan erişimi olması Wi-Fi teknolojisinin önemli avantajlarıdır.

Çalıșma kapsamında Wi-Fi ve Bluetooth teknolojileri ile çalışabilen sabit düğüm cihazları, saha analiz cihazı ve kablosuz takip cihazı olmak üzere 3 farklı donanım geliștirilmiștir. Geliștirilen cihazlar içerisinde ESP32 modülünü barındırmaktadır. Bu cihazların ilki sabit düğüm cihazlarıdır. Sabit düğüm cihazları, her biri yeri değișmeyen erişim noktaları olarak sabit güçte BLE ve Wi-Fi yayın yapmaktadırlar. Şekil 1'de sabit dügümler gösterilmektedir.

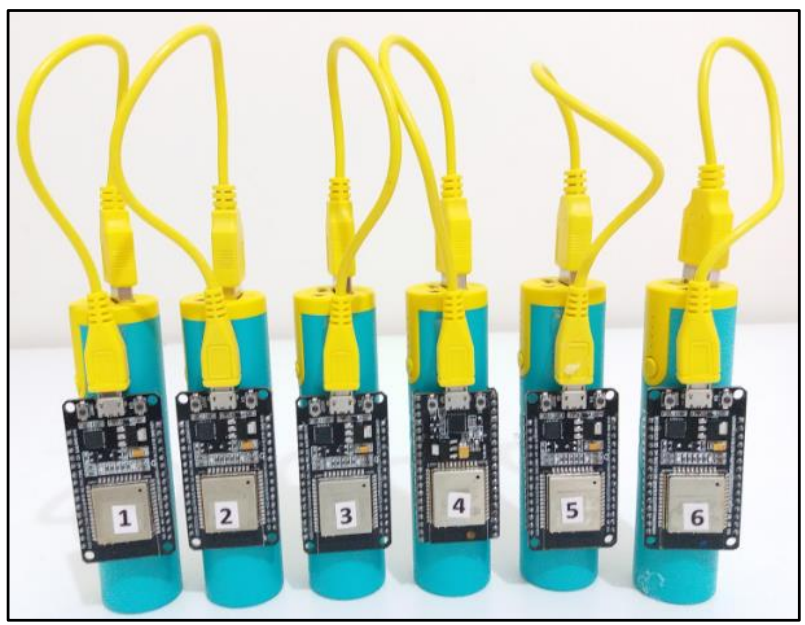

Şekil 1. Çalışma alanına yerleştirilen sabit dügümler (Fixed nodes placed in the work area)

Kapalı alandaki her noktanın yüksek bir kesinlikle bilinebilmesi için ikinci olarak saha analiz cihazı geliştirilmiştir. Saha analiz cihazı da ESP32 modülü içermektedir ve üzerinde butonlar ve bir adet OLED ekran yer almaktadır. Kapalı alan içerisinde konum belirlemek amacıyla öncelikle saha analiz cihazı kullanılmalıdır. Saha analiz cihazına mevcut olarak bulunulan konum metre cinsinden x ve y koordinatı olarak butonlar vasıtasıyla tanımlanır ve ölçüm butonuna basıldığında sabit düğümlerden alınan sinyallerin RSSI değerleri bir bilgisayara gönderilir. Böylece bulunulan konum ve RSSI değerleri kapalı alan içerisindeki her bir konum için toplanarak bilgisayar üzerinde kayıt altına alınmış olur. Bu teknik genel olarak parmak izi yöntemi olarak adlandırılmaktadır. Şekil 2'de tasarlanan saha analiz cihazının şematik çizimi yer almaktadır.

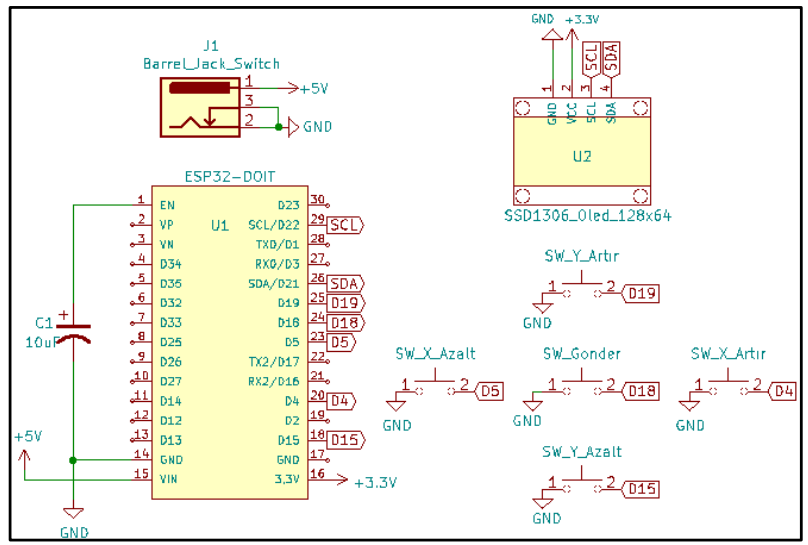

Şekil 2. Tasarlanan saha analiz cihazının şematik çizimi (Schematic drawing of the designed field analyzer)

Şekil 2'de şematik çizimi gösterilen saha analiz cihazı, elektronik devre şeması ve baskı devre kartı tasarım programı olan açık kaynak kodlu KiCad programı kullanılarak çizilmiştir. Baskı devre ve kodlama işlemleri yapılan saha analizi cihazı Şekil 3'de gösterilmektedir.

Şekil 4'te 6 adet düğüm cihazının çalışma alanına yerleştirilmesi ve saha analiz cihazı ile RSSI değerlerinin ölçümü gösterilmektedir. 


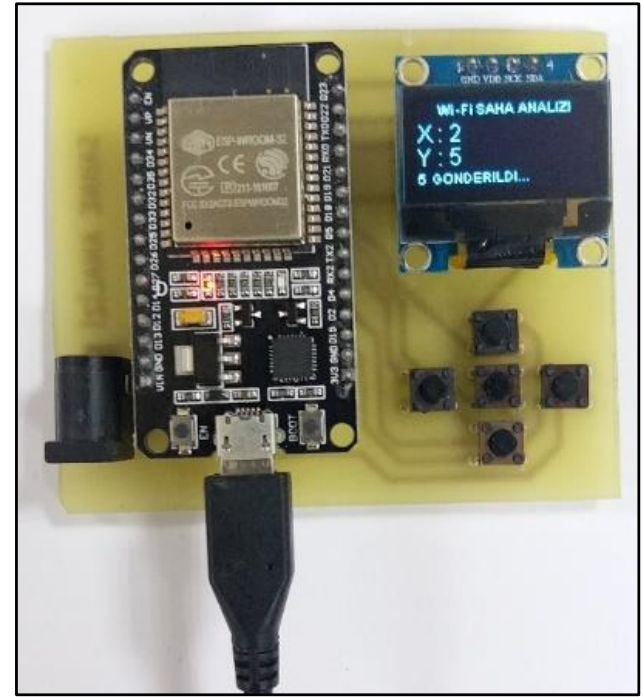

Şekil 3. Geliştirilen saha analiz cihazı (Developed field analyzer)

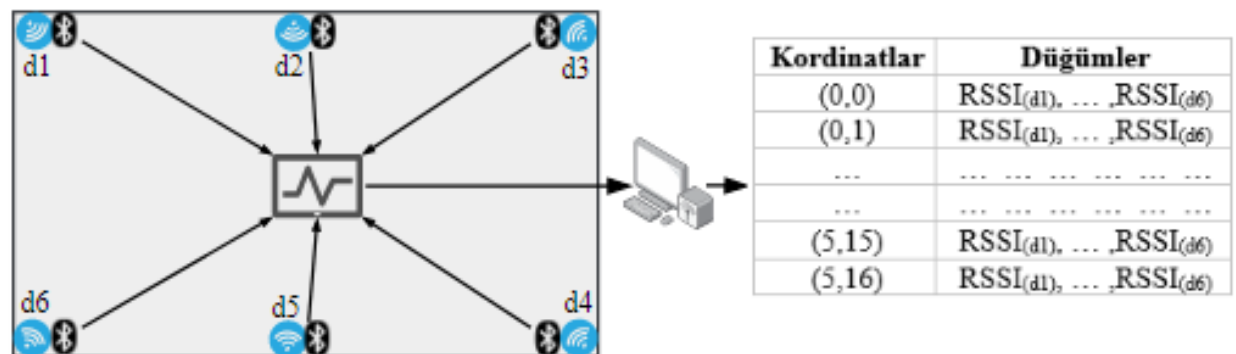

\section{$\mathcal{L} \rightarrow$ Saha Analiz Cihazı \\ (1) - Diuğüm Cihazı}

Şekil 4. Dügüm cihazlarının çalışma alanına yerleştirilmesi ve saha analiz çalışması (Placement of node devices in the work area and field analysis study)

Son olarak kapalı alan içerisinde konumu bulunmak istenen nesneleri tespit etmek için kablosuz takip cihazı geliştirilmiştir. Çevrimdışı safhada, çalışma alanındaki düğümlerden RSSI değerleri elde edilerek çalışma alanının sinyal şiddet haritası oluşturulduktan sonra çalışma alanındaki yapılacak üçüncü ve son işlem kapalı alan içerisindeki konumu bulunmak istenen nesneye bağlanan kablosuz takip cihazı ile düğümlerden yayılan RSSI verilerini almak ve bunları bilgisayara göndermektir. Şekil 5'de bu amaçla geliştirilen kablosuz takip cihazı gösterilmektedir.

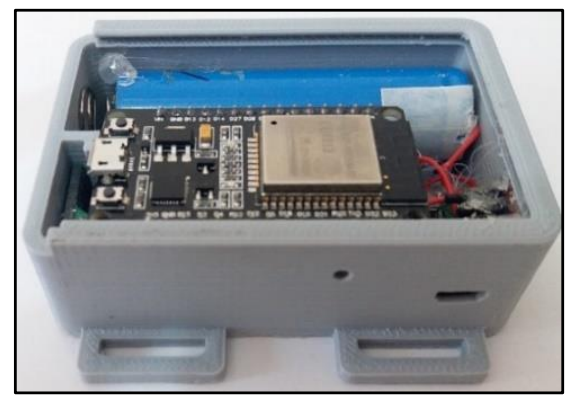

Şekil 5. Geliştirilen kablosuz takip cihazı (Developed wireless tracking device)

Kablosuz takip cihazı ortamdan elde edilen RSSI verilerini bilgisayara gönderir. Bilgisayar, daha önce modellenen çalışma alanının sinyal şiddet haritası ile kablosuz takip cihazından gelen verileri yapay zekâ yöntemleri ile işleyerek hareketli nesnenin konum tespitini gerçekleștirir. Şekil 6'da geliştirilen donanımların tümünde yer alan ESP32 modülü gösterilmektedir. 


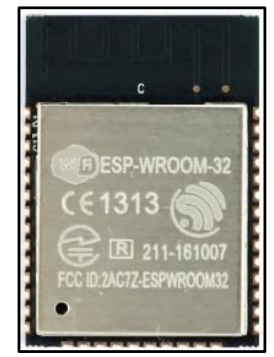

Şekil 6. ESP32 modülü (ESP32 Module)

ESP32 modülü içerisinde ESP32-D0WDQ6 entegresini barındırmaktadır. Bu entegre SoC (System on Chip) olarak tasarlanmıştır. Tek entegre üzerinde Tensilica Xtensa 32-bit çift çekirdekli LX6 CPU, 2.4 GHz Wi-Fi Bluetooth Classic ve Bluetooth Low Energy (BLE) teknolojilerini barındıran, çok çeşitli uygulamalarda kullanılabilecek, farklı güç seçenekleri sunan programlanabilir bir modüldür. Şekil 7'de ESP32 modülünün blok diyagramı gösterilmektedir (Espressif, 2019).

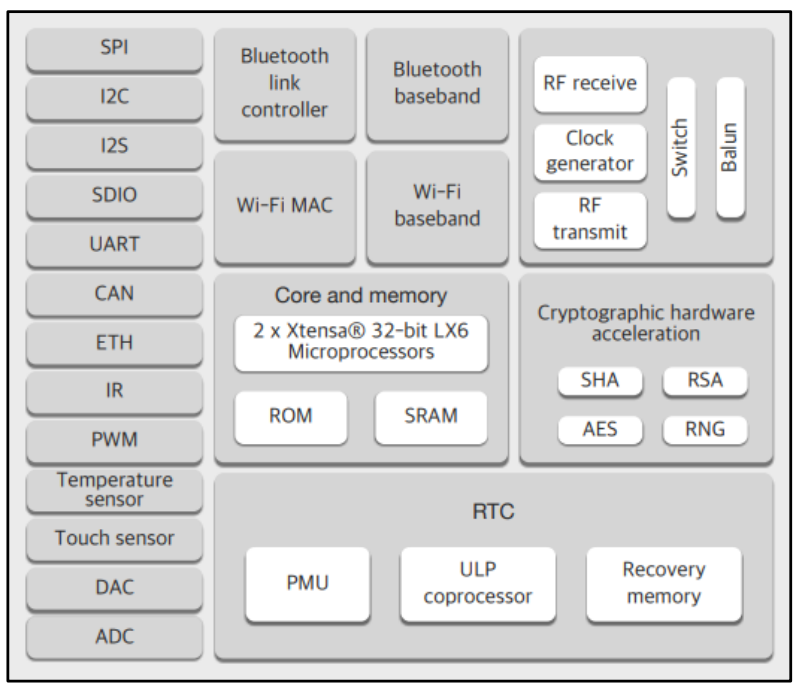

Şekil 7. ESP32-D0WDQ6 blok diyagramı (ESP32-D0WDQ6 block diagram)

ESP32 modülü, esnek bir Wi-Fi kullanımı sunmaktadır. Özellikleri aşağıdaki gibidir. Erişim noktası (EN) olarak çalışarak bir ağ kurabilir, İstasyon (STA) olarak çalışarak bir ağa bağlanabilir ve EN+STA olarak çalışarak hem bir ağ kurup hem de farklı bir ağa bağlanabilir. Ayrıca Wi-Fi Direct özelliği ile daha hızlı dosya paylaşımına olanak sağlar. WPS özelliği ile hızlı bir şekilde şifresiz olarak bağlantı kurulabilir. Bluetooth Low Energy (BLE) ve Bluetooth Classic bağlantı özellikleri ile IoT (Internet of Things) projelerinde çok yönlü olarak kullanılabilir. Tablo 1'de ESP32 modülüne ait enerji tüketim değerleri gösterilmektedir.

Tablo 1. ESP32 modülü güç tüketim değerleri (ESP32 power consumption values)

\begin{tabular}{|l|l|}
\hline ÇALIŞMA MODU & ENERJİ TÜKETİMI \\
\hline Çalışma voltajı & $3.3 \mathrm{v}$ \\
\hline Modem uyku modu & $3-20 \mathrm{~mA}$ \\
\hline Derin uyku modu & $10 \mu \mathrm{A}$ \\
\hline Wi-Fi Tx paket 13dBm-21dBm & $160-260 \mathrm{~mA}$ \\
\hline Wi-Fi / Bt Tx paket 0 dBm & $120 \mathrm{~mA}$ \\
\hline Wi-Fi / Bt Rx ve dinleme & $80-90 \mathrm{~mA}$ \\
\hline
\end{tabular}

Elektrik ile doğrudan bağlantının olmadığı ve modülün harici pil ile çalıștığı alanlarda enerji tüketimi büyük önem arz etmektedir. ESP32 kartının aktif mod, modem uyku modu, hafif uyku modu, derin uyku modu, bekletme modu olmak üzere 5 farklı güç modu bulunmaktadır. Cihaz farklı güç modları kullanılarak çok düşük güç tüketimi ile uzun süre kullanılabilir. 


\section{Konumlandırma Çalışması ve Kullanılan Makine Öğrenmesi Yöntemleri (Positioning Study and Machine Learning Methods Used)}

Geliştirilen konumlandırma cihazları ile 21 metreye 7.5 metrelik bir alanda çalışma yapılmıştır. Toplamda 102 noktadan 510 veri elde edilmiş ve bu veriler K-EYK ve YSA ile eğitilerek konum tahminleri gerçekleştirilmiştir.

\subsection{K-En Yakın Komşu Algoritması (K-Nearest Neighbor Algorithm)}

K-en yakın komşu (K-EYK) sınıflandırma algoritması, belirli özelliklerine göre sınıflandırılmış bir örnek veri kümesine, sınıfı bilinmeyen yeni bir veri geldiğinde, yeni veriyi küme içerisindeki kendisine en yakın K tane veriye bakarak sınıflandırma işlemi yapan bir makine öğrenme algoritmasıdır. K-EYK algoritmasında sınıflandırma işlemleri komşu sayısını ifade eden K parametresine göre yapılmaktadır. K 1 ise örnek veri en yakın komşunun sınıfına atanırken K sayısı veri setindeki örnek sayısına doğru yaklaştıkça dikkate alınan komşu sayısı da artmakta ve oylamaya göre seçim yapılmaktadır (Taşcı ve Onan, 2016).

K-EYK algoritmalarında birçok uzaklık ölçütü kullanılmaktadır. Bunlar arasında Öklid uzaklık, sınıflandırma işlemlerinde en sık kullanılan mesafe ölçüm yöntemidir. Öklid iki nokta arasındaki doğrusal uzaklı̆̆ı hesaplamak için kullanılan bir matematiksel yöntemdir. $x_{i}$ ve $y_{i}$ bilinen iki nokta ve d uzaklık olmak üzere Öklid uzaklık hesabı Denklem (2)'de gösterilmektedir.

$$
d=\sqrt{\sum_{i=0}^{n}\left(x_{i}-y_{i}\right)^{2}}
$$

n Boyutlu iki nokta arasındaki farkların mutlak değerler toplamını ifade eden Manhattan yöntemi Denklem (3)'de gösterilmektedir.

$$
d=\sum_{i=0}^{n}\left|x_{i}-y_{i}\right|^{2}
$$

Chebyshev uzaklığı (en büyük değerin uzaklığı), Minkowski uzaklığının $n \rightarrow \infty$ olduğu özel durumdur ve iki nokta arasındaki farkların mutlak değerlerinin en büyüğü olarak ifade edilmektedir (Taşcı ve Onan, 2016). Denklem (4) Chebyshev uzaklığını göstermektedir.

$$
\mathrm{d}=\max \left(\left|x_{i}-y_{i}\right|\right)
$$

Çalıșma kapsamında gerçekleştirilen konum tahminlerinde, K-EYK sınıflandırma algoritması kullanılarak parmak izi yönteminin doğruluğunun artırılması hedeflenmiştir. Kullanılan diğer makine öğrenmesi yöntemi ise Yapay Sinir Ağlarıdır.

\subsection{Yapay Sinir Ağları (Artificial Neural Networks)}

Yapay zekâ alanının alt dallarından olan yapay sinir ağları (YSA), öğrenebilen sistemlerin temelini oluşturmaktadır. İnsan beynindeki nöronlara benzer şekilde çalışan YSA öğrenme, hatırlama ve yeni bilgiler olușturma gibi ișlevleri yapabilen yazılımlardır (Yurtoğlu, 2005). YSA regresyon, kümeleme, tahmin, sınıflandırma ve optimizasyon gibi alanlarda yaygın olarak kullanılmaktadır (Yılmaz ve Küçüksille, 2014; Bozkurt vd., 2014).

Bir YSA; yapay sinir hücreleri (nöron), hücreler arasındaki bağlantılar ve öğrenme algoritması olmak üzere üç bileşenden oluşmaktadır. YSA'nın temel elemanları olan nöronlar, sistemi etkileyen faktörlere göre bir veya daha fazla girdi alarak problemden istenen sonuç adedi kadar çıktı oluştururlar. Nöronlar bir araya gelerek YSA oluştururlar (Kırbaș, 2018; Salam ve Keskin, 2018). YSA’nın eğitilebilmesi için nöronların ağırlık değerlerinin belirli kurallar dâhilinde değiștirilebilir olması gerekmektedir. Bilgiler tüm ağda yayılmış şekilde tutulurlar ve nöronlar üzerindeki bilgiler tek başlarına anlam taşımazlar çünkü olay tüm ağ tarafından öğrenilir (Öğücü, 2006). Ağdaki tüm nöronların en ideal ağırlık değerlerini almasıyla öğrenme işlemi tamamlanmış olur. Şekil 8'de yapay sinir hücresinin yapısı gösterilmektedir.

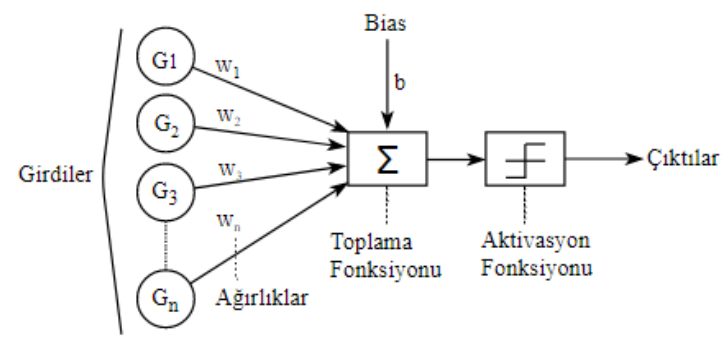

Şekil 8. Yapay sinir hücresi (Artifical Neural cell) 
Çalışma alanından elde edilen sinyal verileri ile YSA eğitmek için MATLAB programı kullanılmıştır. Ağın eğitim için Levenberd-Marquardt öğrenme algoritması kullanılarak veriler \%70 eğitim, \%15 doğrulama, \%15 sınama verisi olmak üzere rastgele bölümlere ayrılmıştır. Levenberd-Marquardt yöntemi hesaplanan hata değerine göre nöron ağırlıklarını yenileyerek en az hata değerini elde eden bir öğrenme algoritmasıdır (Gödekoğlu, 2019). Yapay sinir hücrelerinde birleştirme fonksiyonu için toplama fonksiyonu (5) kullanılmıştır. Gizli katmandaki yapay sinir hücrelerinde hiperbolik tanjant (6), çıktı katmanındaki yapay sinir hücrelerinde doğrusal fonksiyon (7) kullanılmıştır.

$$
\begin{aligned}
& T=\sum_{i=1}^{n} G_{i} w_{i} \\
& \tanh (x)=\frac{e^{x}-e^{-x}}{e^{x}-e^{+x}} \\
& f(x)=x
\end{aligned}
$$

$x$ ve $y$ gerçek konumlar $\hat{x}$ ve $\widehat{y}$, ise tahmin edilen konumlar olmak üzere modellenen YSA performansını ölçmek için Denklem 8'de gösterilmekte olan ortalama kare hatası (MSE) yöntemi kullanılmıştır.

$$
M S E=\left(\frac{1}{n}\right) \sum_{i=0}^{n}\left(\sqrt{(x-\hat{x})^{2}+(y-\widehat{y})^{2}}\right)
$$

Wi-Fi ve Bluetooth sistemleri için YSA modeli Şekil 9'da gösterilmektedir.

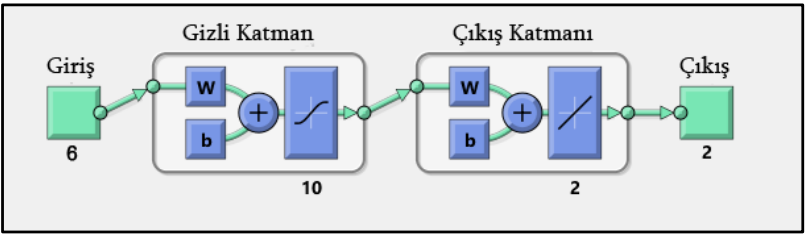

Şekil 9. Yapay Sinir Ağı modeli (Artificial Neural Network model)

Şekil 9'da gösterilmekte olan YSA modeli için girişte çalışma alanındaki 6 düğüm noktasına ait 6 nöron, gizli katmanda 10 nöron ve çıkıșta x ve y koordinatları için 2 nöron bulunmaktadır.

\section{Araştırma Bulguları (Research Findings)}

K-EYK algoritması kullanılarak Wi-Fi ve Bluetooth teknolojileri ile gerçekleştirilen konumlandırma işlemlerinde Manhattan, Öklid, Chebyshev uzaklık hesaplama metotları için K değeri 1 ile 5 arasında sırayla değiştirilerek konum tahminleri gerçekleştirilmiştir. Bu konum tahminleri için yüzde doğruluk sonuçları Tablo 2'de

\begin{tabular}{|c|c|c|c|c|c|c|}
\hline \multirow{2}{*}{ 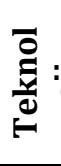 } & \multirow[b]{2}{*}{ Algoritma } & \multicolumn{5}{|c|}{ K sayısı } \\
\hline & & 1 & 2 & 3 & 4 & 5 \\
\hline \multirow{3}{*}{$\frac{1}{3}$} & Öklid & $\%$ 68,6 & $\%$ 60,3 & $\% 58,5$ & $\% 58,5$ & $\% 50,3$ \\
\hline & Manhattan & $\% 69,8$ & $\% 61$ & $\% 59,7$ & $\% 61,5$ & $\% 54,4$ \\
\hline & Chebyshev & $\% 61,5$ & $\% 54,4$ & $\% 49,1$ & $\% 49,1$ & $\% 47,9$ \\
\hline \multirow{3}{*}{ 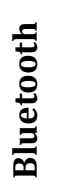 } & Öklid & $\% 47,9$ & $\% 40,2$ & $\% 38,5$ & $\% 34,3$ & $\% 31,4$ \\
\hline & Manhattan & $\% 50,9$ & $\% 41,4$ & $\% 41,4$ & $\% 36,1$ & $\% 34,3$ \\
\hline & Chebyshev & $\% 43,2$ & $\% 30,8$ & $\% 30,2$ & $\% 29$ & $\% 23$ \\
\hline
\end{tabular}
gösterilmektedir.

Tablo 2. K-EYK Sınıflandırma ile Wi-Fi ve Bluetooth sistemlerinin konum tahminlerinin yüzde doğruluk sonuçları (Percentage accuracy of location estimates of K-NN Classification and Wi-Fi and Bluetooth systems)

Tablo 2'deki sonuçlara göre, hem Wi-Fi hem de Bluetooth sistemi için en yüksek doğrulukta konum tahminleri, komşu sayısını belirleyen K değerlerinin 1 olarak alındığı Manhattan uzaklık yöntemi ile hesaplanmıştır. Wi-Fi sistemi ile \% 69,8 oranında doğru sınıflandırma yapılırken, Bluetooth sistemi ile \% 50,9 oranında doğru 
sınıflandırma yapılmıştır. Şekil 10'da Manhattan uzaklık yöntemi ile tespit edilen konumlara ait yüzde hata oranları grafiksel olarak gösterilmektedir.

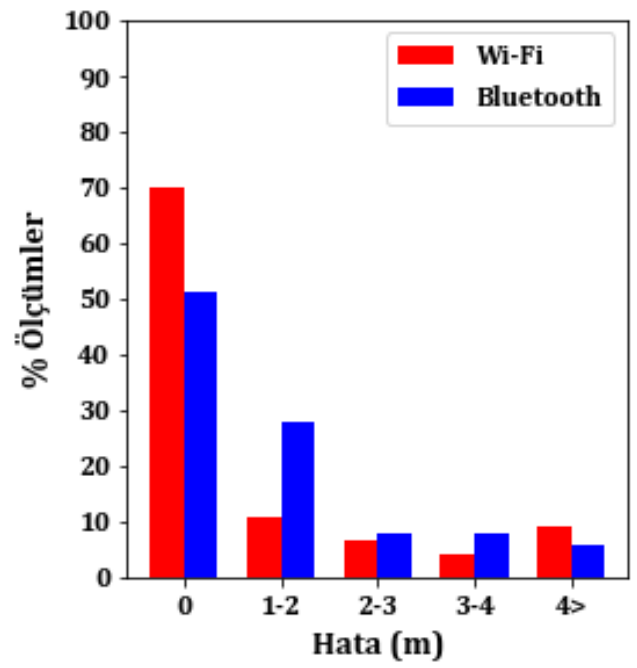

Şekil 10. K-EYK Sınıflandırması ile Wi-Fi ve Bluetooth konumlandırma yüzde hata grafiği (K-NN Classification with Wi-Fi and Bluetooth positioning percentage error graphic)

Şekil 10'daki grafikte Hata (m) ekseni, hedef konum ile tahmin edilen konum arasındaki hatayı metre bazında gösterirken, \% Ölçümler ekseni tüm ölçüm sonuçlarının yüzdelik oranlarını göstermektedir. Wi-Fi sistemi için \% 69.8 doğru sınıflandırma metre bazında değerlendirildiğinde hata ortalaması 0,94 metre hesaplanmıştır. Bluetooth sistemi için \% 50,9 oranındaki doğru sınıflandırma metre bazında değerlendirildiğine hata ortalaması 1,1 metre hesaplanmıştır.

YSA kullanılarak gerçekleștirilen konum tahmin ișlemlerinde Wi-Fi sistemi için Eğitim, doğrulama ve sınama verilerinin logaritmik olarak MSE değerlerini gösteren YSA performans grafiği Şekil 11'de gösterilmektedir.

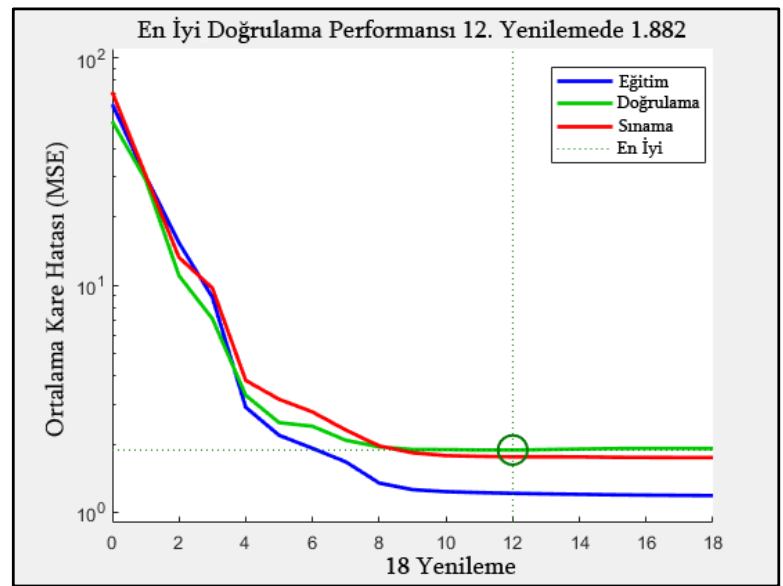

Şekil 11. Wi-Fi YSA eğitim, doğrulama ve sınama performans grafiği (Wi-Fi ANN training, verification and testing performance graph)

Şekil 11'deki grafik incelendiğinde eğitim, doğrulama ve sınama verilerinin birbirine yakın seyir izlediği dolayısıyla ağın genelleme kabiliyetinin iyi olduğu görülmektedir. En düşük MSE değeri 1,882 olarak 12 . yenilemede elde edilmiş ve $18 \mathrm{kez}$ yenilenen ağda 12. yenilemeden sonra anlamlı bir değişiklik görülmemiştir. Şekil 12'de Wi-Fi sisteminin R değerleri eğitim, doğrulama ve sınama verileri için sistemin başarı oranını göstermektedir. 


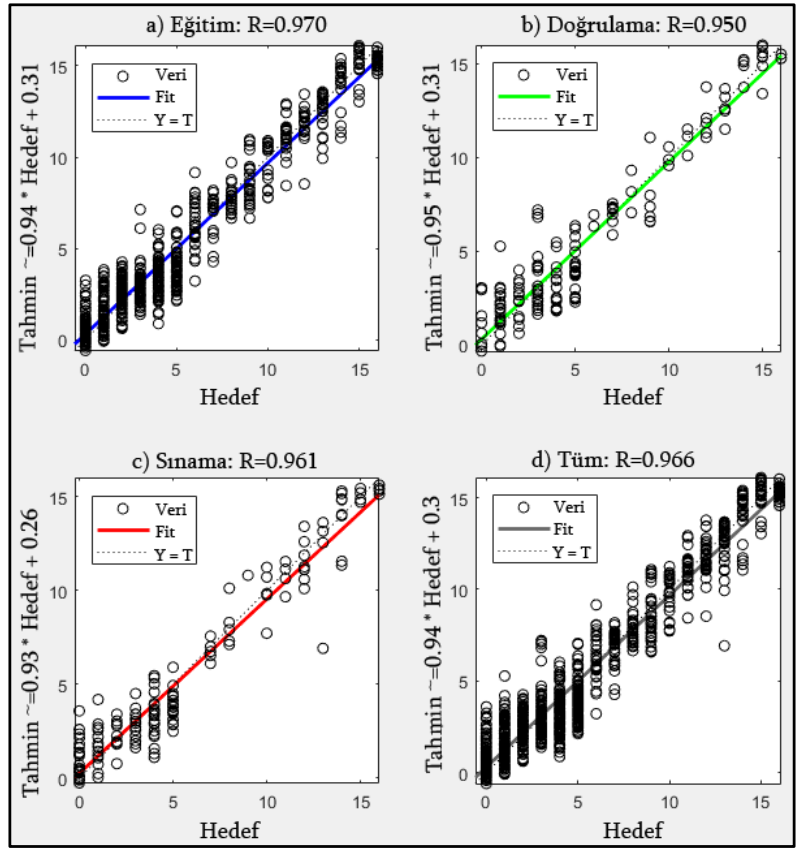

Şekil 12. Wi-Fi YSA regresyon analizi (Wi-Fi ANN regression analysis)

Şekil 12'de gösterilen grafikler incelendiğinde eğitim, doğrulama ve sınama verileri için R değerlerinin birbirine yakın bulunduğu dolayısıyla ağın ezber yapmadığı anlaşılmaktadır. Eğitilen ağın genel başarı grafiğinin yer aldığı Şekil 12.d incelendiğinde R değeri \% 96,6 olarak hesaplanmıştır.

Yine YSA kullanılarak gerçekleștirilen konum tahmin işlemlerinde Bluetooth sistemi için Eğitim, doğrulama ve sınama verilerinin logaritmik olarak MSE değerlerini gösteren YSA performans grafiği Şekil 13'de gösterilmektedir.

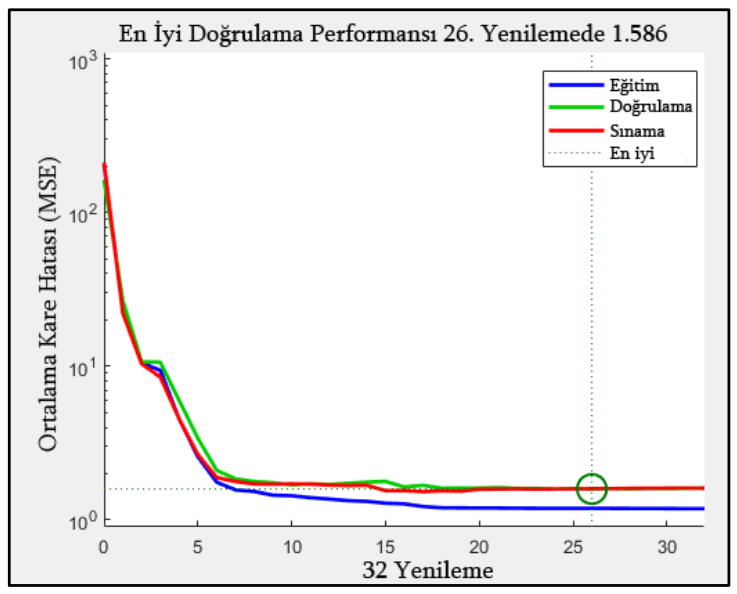

Şekil 13. Bluetooth YSA eğitim, doğrulama ve sınama performans grafiği (Bluetooth ANN training, verification and testing performance graph)

Şekil 13 incelendiğinde en düşük MSE değeri 1,586 olarak 26. yenilemede elde edilmiş ve 32 kez yenilenen ağda 26. yenilemeden sonra anlamlı bir değişiklik görülmemiştir.

Şekil 14'de Bluetooth sisteminin R değerleri eğitim, doğrulama ve sınama verileri için sistemin başarı oranını göstermektedir. Şekil 14'deki grafiklerde eğitilen ağın genel başarı grafiğini gösteren Şekil 14.d incelendiğinde R değeri \% 96,9 olarak hesaplanmıştır. Şekil 15’de Wi-Fi ve Bluetooth sistemlerine ait yüzde hata oranları grafiksel olarak gösterilmektedir. 


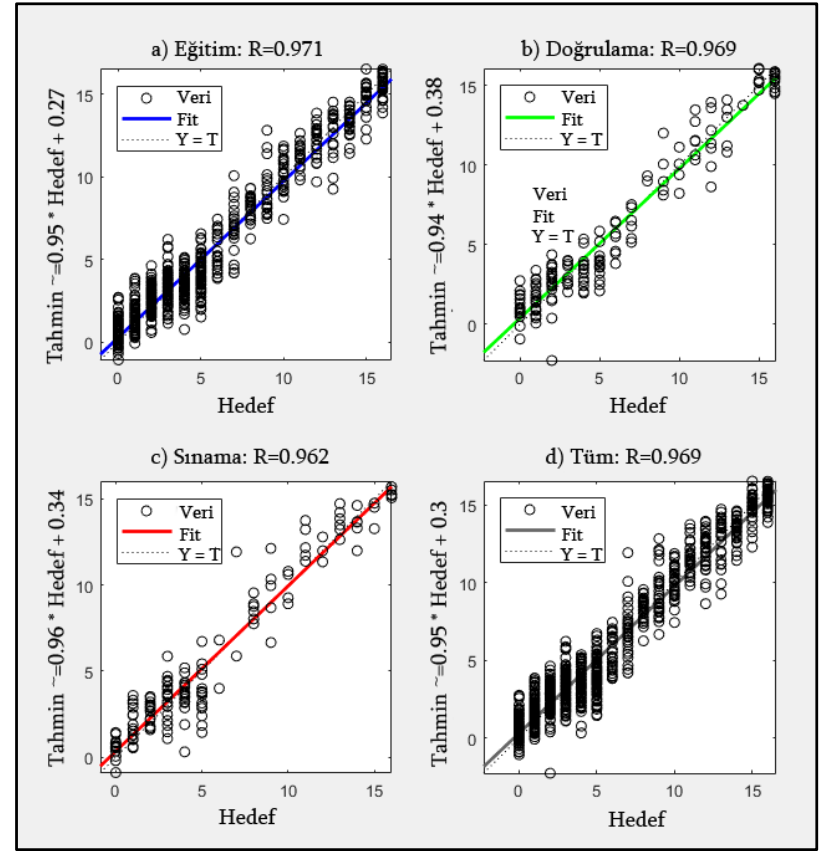

Şekil 14. Bluetooth YSA regresyon analizi (Bluetooth ANN regression analysis)

Tablo 3. YSA eğitiminin başarı ve hata değerlerinin karşılaştırılması (Comparison of success and error values of ANN education)

\begin{tabular}{|c|c|c|c|c|}
\hline Teknoloji & Değerler & Örnek sayısı & MSE & $\mathbf{R}$ \\
\hline \hline \multirow{3}{*}{ Wi-Fi } & Eğitim & 356 & 1,188 & 0,971 \\
\cline { 2 - 5 } & Doğrulama & 77 & 1,586 & 0,969 \\
\cline { 2 - 5 } & Sinama & 77 & 1,596 & 0,962 \\
\hline \multirow{3}{*}{ Bluetooth } & Eğitim & 356 & 1,213 & 0,970 \\
\cline { 2 - 5 } & Doğrulama & 77 & 1,882 & 0,950 \\
\cline { 2 - 5 } & Sinama & 77 & 1,756 & 0,961 \\
\hline
\end{tabular}

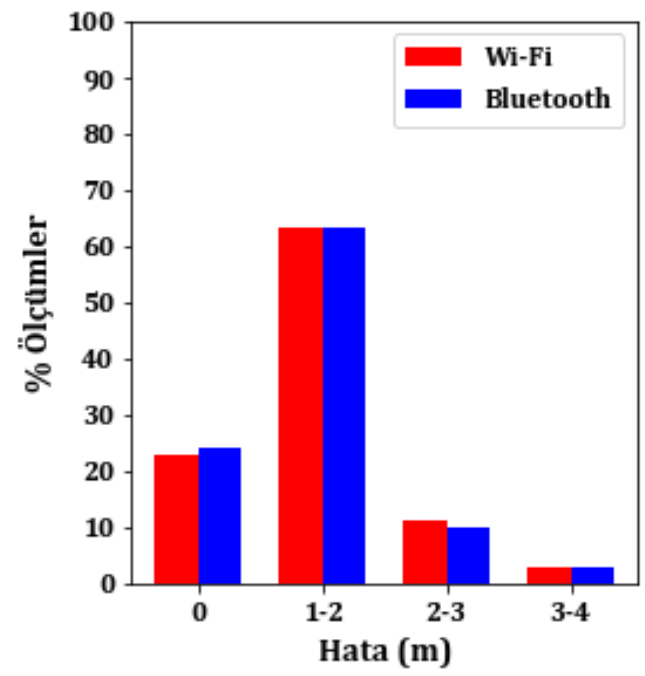

Şekil 15. YSA ile Wi-Fi ve Bluetooth konumlandırma yüzde hata grafiği (ANN with Wi-Fi and Bluetooth positioning percentage error graphic)

Şekil 15'te metre bazında hata değerleri gösterilirken, YSA ile Wi-Fi ile gerçekleştirilen konum tahminlerinde ortalama 1,51 metre, Bluetooth ile gerçekleștirilen konum tahminlerinde ortalama 1,48 metre hata ile konum tespitleri gerçekleștirilmiştir. 


\section{Sonuç ve Tartışma (Result and Discussion)}

Kapalı alan konumlandırma sistemleri gelişmekte olan bir teknolojidir. Çalıșma kapsamında kapalı alan konumlandırma sistemlerinde kullanılmak üzere ESP32 modülü üzerine kurulu olarak 3 farklı donanım geliştirilmiştir. Donanımlardan ilki sabit düğüm olarak adlandırılmaktadır ve erişim noktası olarak görev yapmaktadır. İkinci donanım, kapalı alandaki sabit erişim noktalarının belli bir noktadaki RSSI sinyal güçlerini ölçebilen ve elde ettiği değerleri bir bilgisayara aktarabilen saha analiz cihazıdır. Geliştirilen son donanım ise takip edilip konumu belirlenmek istenen nesneye yerleștirilecek olan enerji kaynağı olarak bir adet Li-Po batarya kullanan kablosuz takip cihazıdır. Bu cihaz da yine sabit erişim noktalarının yaydıkları sinyal güçlerini ölçerek bir bilgisayara aktarmakta ve böylece konumun hesaplanmasını sağlamaktadır. Geliştirilen üç cihaz da Wi-Fi ve BLE olarak kullanılabilmektedir. Konum tespitinde K-EYK ve YSA teknikleri kullanılarak konumlandırma hatasının en aza indirgenebilmesi amaçlanmıştır. Kullanılan teknolojiye ve yapay zekâ tekniğine bağlı olarak konum tespitinin değiştiği gözlenmiş̧tir. K-EYK algoritması kullanıldığında Wi-Fi ve Bluetooth sistemleri için 1 metre hatalı konum tespiti yapılmıştır. YSA algoritması kullanımında ise Wi-Fi ve Bluetooth sistemleri için 1.5 metre hatalı konum tespiti yapılmıştır. Literatür incelendiğinde de, RSSI tabanlı konumlandırma sistemleri için metreler mertebesinde hatalı hesaplamaların yapıldığı görülmüştür. Sinyal ölçümlerinde, konum değiştirilmediğinde dahi RSSI değerlerinde sapmalar olduğu tespit edilmiştir. Bu durum hatalı konum belirlemelerine sebep olmaktadır. Bunun temel sebebi ucuz bir yöntem olan RSSI ölçümünün sağlıklı olarak yapılamaması olabilir. Literatürde Wi-Fi veya Bluetooth tabanlı sistemler ile kapalı alanlarda konum tespit çalışmalarına sıklıkla rastlanırken hem Wi-Fi hem de Bluetooth tabanlı olarak çalışabilen konumlandırma sistemi geliştirilmesi ve çalışmada kullanılan cihazların özel olarak tasarlanması çalışmanın özgün taraflarıdır. İlerleyen zamanlarda elde edilen verilerin en az hatayla değerlendirilmesine yönelik çalışmalar yapılması planlanmaktadır.

\section{Çıkar Çatışması (Conflict of Interest)}

Yazarlar tarafından herhangi bir çıar çatışması beyan edilmemiştir. No conflict of interest was declared by the authors.

\section{Kaynaklar (References)}

Abu Salam, Z., Keskin M. E. (2018). Yapay Sinir Ağları ile Dibis Barajı'nın Seviye Tahmini. Mühendislik Bilimleri ve Tasarım Dergisi 6(4), $564-569$.

Arslan, K. (2019). Yapay Zekâ Teknikleri ile Wi-Fi ve Bluetooth Tabanlı Kapalı Alan Konumlandırma Sistemi Geliştirilmesi. Burdur Mehmet Akif Ersoy Üniversitesi.

Arslan, K., Kirbaş, İ. (2016). Nesnelerin İnterneti Uygulamaları İçin Algılayıcı/Eyleyici Kablosuz Düğüm İlkörneği Geliştirme. Mehmet Akif Ersoy Üniversitesi Fen Bilimleri Enstitüsü Dergisi, 7(Özel 1), 35-43.

Aydin, H., Erkmen, B. (2019). Kapalı Alan Yaya Konumlandırma Sistemi. Mühendislik Bilimleri ve Tasarım Dergisi, 7(2), 337344.

Başak, A.A. (2017). Izgara Tabanlı Parmak İzi Algoritmalarıyla Kapalı Alan Konumlandırma Optimizasyonu, Yüksek Lisans Tezi. Ankara Üniversitesi.

Bekkelien, A. (2012). Bluetooth Indoor Positioning, Master of Computer Science. Geneva Üniversitesi, İsviçre.

Bulucu, U., Kavas, A. (2007). Kablosuz Ağ Kapsaması için YSA(Yapay sinir Ağ) Modeli Kullanılarak Propagasyon Kayıplarının Hesaplanmasi.

Corbacho Salas, A. (2014). Indoor Positioning System based on Bluetooth Low Energy, A Degree's Thesis. Universitat Politècnica de Catalunya, Barcelona.

Dahlgren, E., Mahmood, H. (2014). Evaluation of indoor positioning based on Bluetooth Smart technology. Yüksek Lisans Tezi. Chalmers Teknoloji Üniversitesi. İsveç.

Doğancı, Y. U. (2008). 802.11 Standartlarını Kullanarak Pozisyon Tespiti. TOBB Ekonomi ve Teknoloji Üniversitesi.

Dükkancl, A., Kırbaș, İ. (2018). Designing a web based data acquisition system for battery-powered wireless sensor nodes: WiFiLab. IV International Conference on Engineering and Natural Science (ICENS), 1, 439-447. http://www.icens.eu

$\begin{array}{llllll}\text { Espressif, } & \text { S. } & \text { (2019). } & \text { ESP32 } & \text { Series } & \text { Datasheet. }\end{array}$ Https://www.espressif.com/sites/default/files/documentation/esp32_datasheet_en.pdf (Erişim Tarihi 02.01.2020).

Gödekoğlu, D. A. (2019). Yapay Sinir Ağları Kullanılarak Solunum Fonksiyon Testleri ile Cinsiyet, Obezite e Sigara Kullanımının İlişkilendirilmesi, Yüksek Lisans Tezi. Sakarya Üniversitesi Fen Bilimleri Enstitüsü, Türkiye.

$\mathrm{Gu}$, Y., Lo, A., Niemegeers, I. (2009). A survey of indoor positioning systems for wireless personal networks. IEEE Communications Surveys Tutorials, 11(1), 13-32. https://doi.org/10.1109/SURV.2009.090103

Kırbaș, İ. (2018). İstatistiksel metotlar ve yapay sinir ağları kullanarak kısa dönem çok adımlı rüzgâr hızı tahmini. SAÜ Fen Bilimleri Enstitüsü Dergisi, 1-1. https://doi.org/10.16984/saufenbilder.305224

Kırbaş, İ., Dükkancı, A. (2019). Development of A Wi-Fi Based Indoor Location System Using Artificial Intelligence Techniques. $2(1), 5$.

Kim, J., Lee, I. (2015). 802.11 WLAN: history and new enabling MIMO techniques for next generation standards. IEEE Communications Magazine, 53(3), 134-140. https://doi.org/10.1109/MCOM.2015. 7060495

Kolodziej, K. W., Hjelm, J. (t.y.). Local Positioning Systems: LBS Applications and Services. 62. 
Lashkari, A. H., Parhizkar, B., Ngan, M. N. A. (2010). WIFI-Based Indoor Positioning System. 2010 Second International Conference on Computer and Network Technology, 76-78. https://doi.org/10.1109/ICCNT. 2010.33

Mautz, R. (2012). Indoor positioning technologies. http://hdl.handle.net/20.500.11850/54888

Michaelsson, L., Quiroga, S. (2017). Design and Evaluation of An Adaptive Dairy Cow Indoor Positioning System, Master of Science Thesis. KTH Royal Institute of Technology School of Industrial Engineering and Management, İsveç.

Öğücü, Müh. M. O. (2006). Yapay Sinir Ağları ile Sistem Tanıma. Yüksek Lisans Tezi. İstanbul Teknik Üniversitesi.

Sakpere, W., Oshin, M. A., Mlitwa, N. (2017). A State-of-the-Art Survey of Indoor Positioning and Navigation Systems and Technologies. South African Computer Journal, 29(3). http://sacj.cs.uct.ac.za/index.php/ sacj/article/view/452

Taşcı, E., Onan, A. (2016). K-En Yakın Komşu Algoritması Parametrelerinin Sınıflandırma Performansı Üzerine Etkisinin İncelenmesi. Akademik Bilișim.

Taşkın, D. (2017). Design of Bluetooth Low Energy Based Indoor Positioning System. Balkan Journal of Electrical and Computer Engineering, 60-65. https://doi.org/10.17694/bajece.334388

Türkoral, T., Tamer, Ö., Yetiş, S., İnanç, E., Çetin, L., (2016). Alınan İșaret Güç Göstergesi (RSSI) Metriği Kullanılarak Kapalı Alan Mesafe Kestirimi, Elektrik-Elektronik ve Biyomedikal Mühendisliği Konferansı

Algorithm (SBA) For Trainin Feed-Forward Neural Network. 20th International Conference on Soft Computing.

Yılmaz, S., Küçüksille, E. U. (2014). Strengthened Bat Algorithm (SBA) For Trainin Feed-Forward Neural Network. 20th International Conference on Soft Computing.

Yurtoğlu, H. (2005). Yapay Sinir Ağları Metodolojisi ile Öngörü Modellemesi: Bazı Makroekonomik Değișkenler İçin Türkiye Örneği.

Yücel, H., Yazıcl, A., ve Edizkan, R. (2014). A survey of indoor localization systems. 2014 22nd Signal Processing and Communications Applications Conference (SIU). 